\title{
Piezoelectric actuator: Searching inspiration in nature for osteoblast stimulation
}

\author{
C. Frias ${ }^{\mathrm{a}, *, 1}$, J. Reis ${ }^{\mathrm{b}, * *, 1}$, F. Capela e Silva ${ }^{\mathrm{c}, 3}$, J. Potes ${ }^{\mathrm{b}, 3}$, J. Simões ${ }^{\mathrm{d}, 4}$, A.T. Marques ${ }^{\mathrm{a}, 2}$ \\ ${ }^{a}$ Departamento de Engenharia Mecânica e Gestão Industrial, Faculdade de Engenharia, Universidade do Porto (FEUP), Rua Roberto Frias s/n, 4200-465 Porto, Portugal

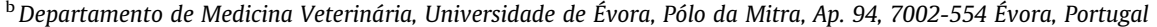 \\ ${ }^{\mathrm{c}}$ Institute of Agrarian and Environmental Mediterranean Sciences and Department of Biology, University of Évora, 7002-554 Évora, Portugal \\ ${ }^{\mathrm{d}}$ Departamento de Mecânica, Universidade de Aveiro, Campus de Universitário de Santiago, s/n, 3810-193 Aveiro, Portugal
}

\section{A R T I C L E I N F O}

\section{Article history:}

Available online 7 July 2010

\section{Keywords:}

A. Smart material

Polymeric piezoelectric

C. Finite element analysis (FEA)

C. Stress concentrations

\begin{abstract}
A B S T R A C T
Bone is a composite with piezoelectric properties. Bone mass and structure are dependent on mechanical stress and adaptive response at cellular and tissue levels, but the role piezoelectricity plays in bone physiology is yet to be understood. Physical activity enhances bone density, through mechanical stimulation. Osteocytes and osteoblasts are essential for mechanosensing and mechanotransduction. Strategies have been tested for mechanical stimulation of cells and tissues in vitro. The aim of this work was to experimentally validate the use of piezoelectric materials as a mean of directly straining bone cells by converse piezoelectric effect. To estimate the magnitude of stress/strain, finite numerical models were applied and theoretical data was complemented by optic experimental data. Osteoblasts were then grown on the surface of the piezoelectric material and cell response studied.
\end{abstract}

(c) 2010 Elsevier Ltd. All rights reserved.

\section{Introduction}

Bone is a composite material with three chief components: collagen, apatite and water. In cortical bone, the densely packed collagen fibrils are arranged in concentric lamellae, each lamellae is $2-3 \mu \mathrm{m}$ thick and is arranged in several discrete layers of parallel fibrils, each layer having a different orientation of fibrils. Apatite crystals (mainly carbonated apatite) are deposited within and around these fibrils [1]. Both cancellous and compact bone show anisotropic behavior, i.e. the Young's modulus depends on the direction of the load, due to the deliberate direction of lamellae $[2,3]$. Apart from endocrine, paracrine factors and serum calcium levels, bone remodeling is dependent of mechanical environment. Strain magnitude, frequency and loading duration influence bone remodeling. According to Turner, three essential rules determine bone remodeling: cell responses depend upon the strain, load and frequency of the stimulus; dynamic, short loading exerts the strongest bone adaptation response, and bone cells tend to accom-

\footnotetext{
* Corresponding author. Tel.: +351 225081721; fax: +351 225081445

** Corresponding author. Tel.: +351 266760840; fax: +351 266760944.

E-mail addresses: clara.frias@fe.up.pt (C. Frias), jmfcr@uevora.pt (J. Reis), fcs@uevora.pt (F. Capela e Silva), jacpotes@uevora.pt (J. Potes), jsimoes@mec.ua.pt (J. Simões), marques@fe.up.pt (A.T. Marques).

1 These authors contributed equally to this work

2 Tel.: +351 225081721; fax: +351225081445.

3 Tel.: +351 266760840; fax: +351266760944

4 Tel.: +351 234370200; fax: +351234370985.
}

modate to a routine, so the stimulus must vary in order to elicit a same level of response [4-10]. Osteocytes and osteoblasts are key elements in mechanical stimuli sensing and transduction in living bone. Several substances produced by osteoblasts function as messenger molecules, in response to mechanical stimuli, like prostaglandins (particularly $\mathrm{PGE}_{2}$ ) and nitric oxide [11-15].

The bone has piezoelectric properties, as Fukada and Yasuda described [16]. Piezoelectricity has been reported for other natural composites like dentin, skin and tendon $[17,18]$. In these tissues, as in bone, piezoelectricity is most likely dependent on collagen fibrils $[18,19]$. Mechanical loads in bone are translated into potential variation, in what is known as direct piezoelectric effect; in the inverse effect, submitting bone to an electric field induces deformation. However, the role of piezoelectric effect in bone healing and remodeling has not yet been fully understood.

A broad variety of devices have been tested for mechanical stimulation of cells and tissues in vitro, namely of osteocytes and osteoblasts [20-24], but many of these systems are difficult to adapt to an in vivo situation. Takada reported the use for in vitro assays of a piezoelectric actuator in which the cells were seeded on a collagen gel block; the displacement was originated by two piezoelectric ceramic layers subjected to electric current [24]. Rodrigues et al. describe enhanced proliferation, attachment and phosphatase alkaline activity levels on goat bone marrow cells seeded on the surface of $\beta$-PVDF membranes, especially when cultures were subjected to agitation, and suggest this may be due to the $\beta$-PVDF piezoelectrical properties (by direct piezoelectric effect) [25]. 


\section{Methods}

\subsection{Polymeric piezoelectric substrate}

\subsubsection{Physical phenomena of the piezoelectric substrate}

The polymeric piezoelectric films used (Polyvinylidene Fluoride (PVDF)) were supplied by Measurement Specialties Inc. Company (USA). These thin films consist of an $12 \times 13 \mathrm{~mm}$ active area, printed with silver ink electrodes on both surfaces in an $15 \times 40 \mathrm{~mm}$ die-cut piezoelectric polymer substrate. It is polarized along the thickness and admits as piezoelectric strain constants $d_{z y}=23 \times 10^{-12}$ and $d_{z z}=-33 \times 10^{-12}\left(\frac{m}{m} / \frac{V}{m}\right)$, see Fig. 1 . Theoretically, based on the converse piezoelectricity effect, when a voltage is applied along the polarized direction (axis- $z z$ ), the polymer strains in the directions $y$-axis, given the intrinsic properties of this specific material. The amount of free strain is given by the following equation.

$\varepsilon_{y y}=\frac{d_{z y}}{t} V_{a}$

where $t$ is the polymer thickness, and $V_{a}$ the applied voltage.

\subsubsection{Coating the polymeric piezoelectric substrate with PMMA and} micro-particles of Bonelike

To ensure adhesion of osteoblasts to the device surface and electric insulation, the surface was uniformly covered with an electric insulator material. The chosen material for covering was an acrylic, poly (methyl methacrylate) (PMMA), (PERFEX ${ }^{\circledR}$, International Dental Products, USA), used alone in the first three layers and a in forth layer along with $4 \%$ of Bonelike ${ }^{\circledR}(250-500 \mu \mathrm{m})$ particles added (kindly offered by INESCPorto).

The coating was performed by dip-coating at constant velocity of $0238 \mathrm{~mm} / \mathrm{s}$. Impedance was measured both in saline and culture medium, in non-coated and coated devices, and electric insulation achieved. The impedance was infinite in the coated devices.

\subsubsection{Device sterilization process}

The coated polymeric piezoelectric substrates were submitted to $\gamma$-irradiation (normed dosis of $25 \mathrm{kGy}$ ) for sterilization prior to cell culture (ITN, Lisbon).

\subsection{Finite numerical method (FNM)}

FNM estimated and quantified the amount of stress/strain distribution along the piezoelectric surface. The mesh was of quadratic piezoelectric solid elements with three degrees of freedom, through Finite Elements Analysis (FEA) using the solver Abaqus $6.7-1$ in static conditions. The material properties used for the numerical simulation were provided by the supplier. The model was composed by 9109 nodes.

\subsection{Electronic Speckle Pattern Interferometry process (ESPI)}

To experimentally understand and quantify the real amount of the displacement and its distribution along the piezoelectric actuator surface ESPI was used (LOME-INEGI). The displacement in coated and uncoated devices in the center of the active area was compared along the three axes: $x, y$ and $z$.

\subsection{Cell culture}

The cell line used, MC3T3-E1 cells exhibit a developmental sequence typical for osteoblasts [26] and has been used in many studies addressing the effects of mechanical stimulation [27-29].

MCT3T3-E1 cells were cultured under standard conditions, using $\alpha$-MEM medium (Cambrex), $2 \mathrm{~mm}$ L-glutamine (Cambrex), $10 \%$ of bovine fetal serum (Gibco), $0.5 \%$ gentamicin and $1 \%$ amphotericin B (Gibco).

Piezoelectric substrates (standing on culture dishes, TPP) and controls (standard culture dishes, TPP) were seeded with $16 \times 10^{4}$ cells, with a total volume of $100 \mu \mathrm{l}$ of cell suspension. Cells were allowed to adhere to the substrate, then the rest of culture medium added $(n=6)$; and cells grown in both static and dynamic piezoelectric substrates. On the substrates submitted to dynamic conditions, stimulation was done with a alternating sinusoidal current (AC), of $5 \mathrm{~V}$, at $1 \mathrm{~Hz}$ and $3 \mathrm{~Hz}$ for $15 \mathrm{~min}$ at each frequency ( $24 \mathrm{~h}$ post-seeding). All experiments were repeated three times (see, Figs. 1 and $2 \mathrm{a}$ and b).

\subsubsection{Viability and metabolic activity}

The resarzurin-based method utilizes the redox dye resarzurin that upon reduction by metabolically active cells is converted into a highly fluorescent product (resorufin). Nonviable cells have no metabolic capacity and, thus, will not reduce the dye. Therefore, the fluorescence intensity observed in this assay is a measure of the viable cells [30-32].

After stimulation, the medium was replaced with new medium with $10 \%$ resarzurin solution. Cells cultures were then incubated for $3 \mathrm{~h}$ before collection of samples and fluorescence readings done using a fluorescence spectrophotometer (Shimadzu, Japan).

\subsubsection{Total protein content}

Cellular protein content was measured in cell lysate supernatant with a BCA protein assay kit, according to the manufacturer's instructions (Pierce, USA). The resulting optical densities were measured at $570 \mathrm{~nm}$ with a CODA spectrophotometer. Bovine serum albumin was used to generate a standard curve.

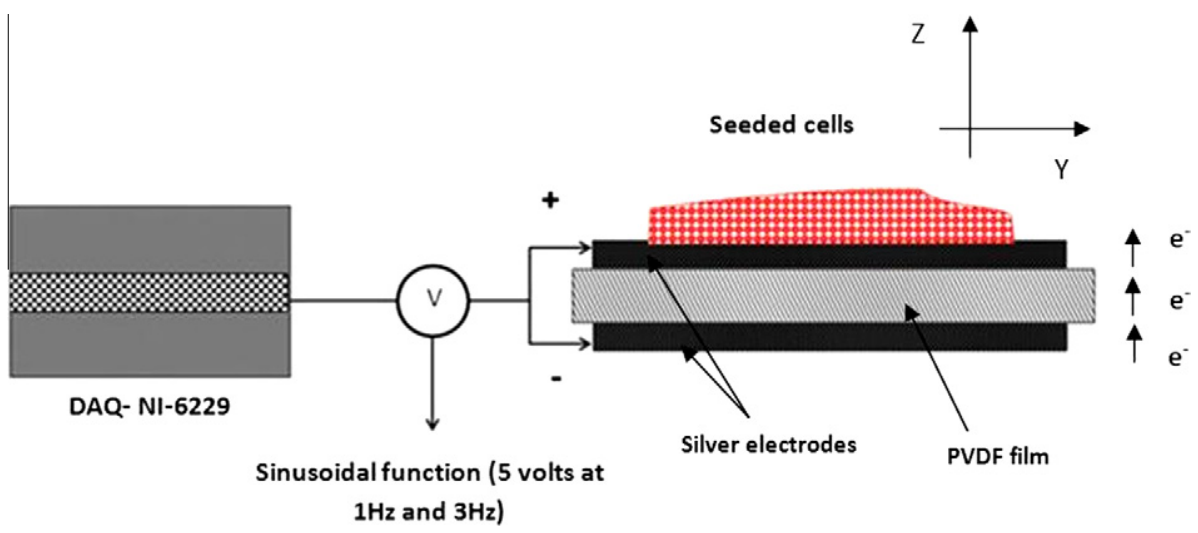

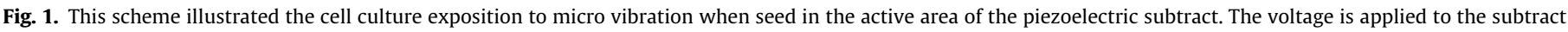
with frequencies of $1 \mathrm{~Hz}$ and $3 \mathrm{~Hz}$. 

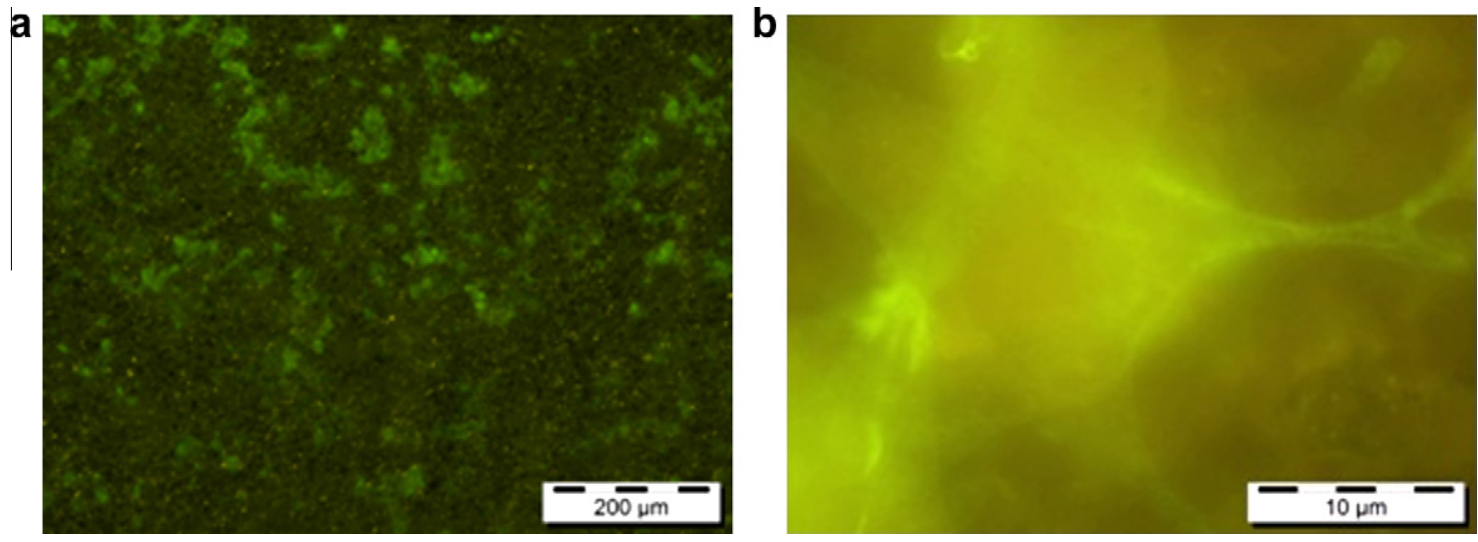

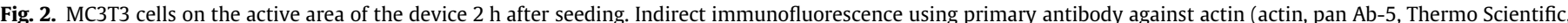

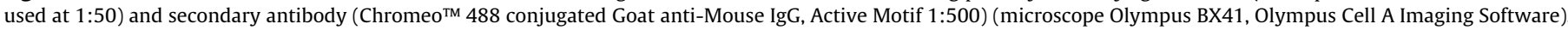

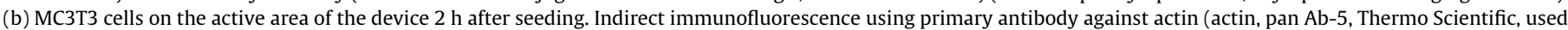
at 1:50) and secondary antibody (Chromeo ${ }^{\mathrm{TM}} 488$ conjugated Goat anti-Mouse IgG, Active Motif 1:500); (microscope Olympus BX41, Olympus Cell A Imaging Software).

\subsubsection{Nitric oxide (NO)}

NO is a messenger molecule produced in response to mechanical stimulation of osteoblasts and osteocytes, with a large variety of biological functions [13,33]. In this study, culture medium samples were collected immediately after stimulation and NO measured, using NO Assay Kit (Biochain), based on the Griess reaction, according to the manufacturer's instructions. NO levels are presented normalized for total protein content.

\subsubsection{Statistical analysis}

Normal distribution of the results was verified using the Shapiro-Wilk normality test for $n>3$, and differences between groups tested using one-way ANOVA and significant differences were considered at a $P$ value 0.05 . The statistical analysis was done using software OriginPro 7.5 (OriginLab Corporation, USA).

\section{Results}

\subsection{Deposition of thin films in the piezoelectric actuators}

Fig. 3a and $b$ shows the active area already coated. The device has a total thickness of $72 \mu \mathrm{m}$, and the electrical isolation of the surface was guaranteed.

\subsection{Finite numerical method}

FNM gave an estimation of strain and displacement distribution along the polymeric piezoelectric surface. The values range in the $y$ -direction are $-1.07<y>56.1(\mathrm{~nm})$. The higher displacement was observed in the piezoelectric free extremity (see Fig. 4). In the $x$ direction is observed a minimal displacement resulting from the piezoelectric material properties, namely the Poisson coefficient (see Fig. 5). It is possible to observe a sinusoidal numerical perturbation in the encastre region, but the strain values are around $\varepsilon_{y y}=2.2 \mu \varepsilon$ along the piezoelectric surface (see Fig. 6). These values are near the theoretical ones, see Eq. (1).

\subsection{Electronic Speckle Pattern Interferometry process (ESPI)}

The behavior of the piezoelectric film, for a potential differential of $5 \mathrm{~V}$, was also studied experimentally through the holographic procedure Electronic Speckle Pattern Interferometry (ESPI). The behavior in uncoated and coated films sterilized by $\gamma$-irradiation was studied along the orthonormal plan.

Figs. 7 and 8 show the tridimensional behavior of the uncoated and coated films. The displacement is higher in the uncoated film, and higher levels of displacement occur in the free end of the film. The coated film shows a reduction of approximately $50 \%$ in the a

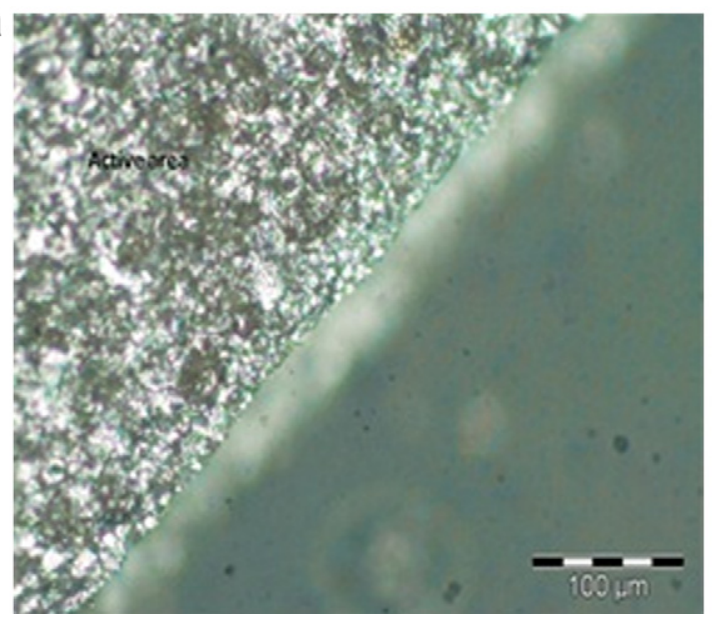

b

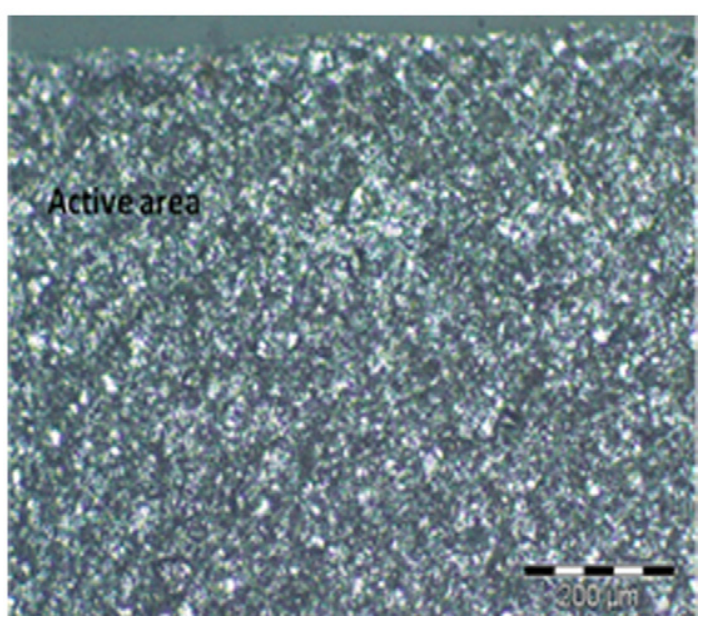

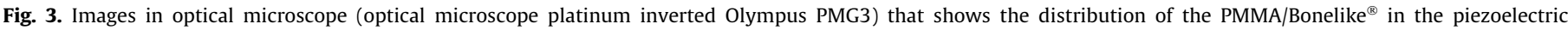
membrane. 


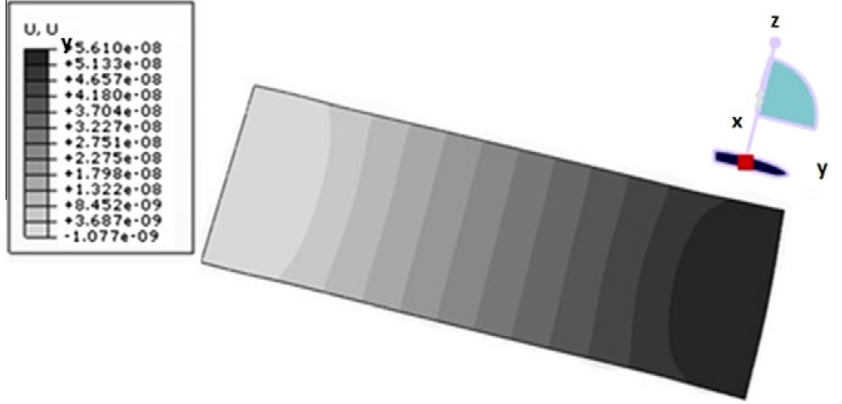

Fig. 4. Displacement in direction $y y$, direction of the piezoelectric effect, to a potential difference of $5 \mathrm{~V}$ in a mesh with 9109 nodes.

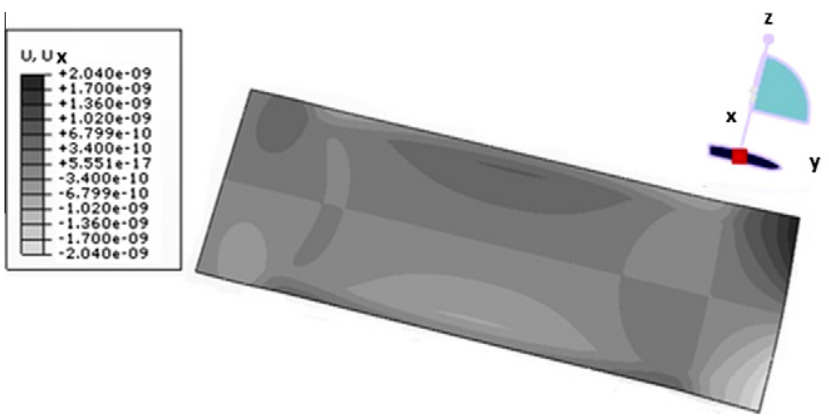

Fig. 5. Displacement in the $x x$ direction, the transverse piezoelectric effect, to a potential difference of $5 \mathrm{~V}$ in a mesh with 9109 nodes.

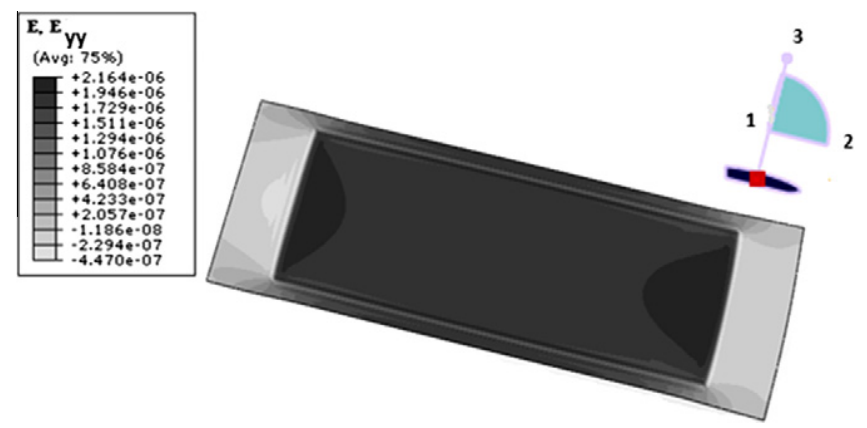

Fig. 6. Strain distribution in direction $y y$, direction of the piezoelectric effect, to a potential difference of $5 \mathrm{~V}$ in a mesh with 9109 nodes.

maximum displacement values, and these take place in the center of the active area, corresponding also to the area of higher cell density.

\subsection{Cell culture}

\subsubsection{Viability and metabolic activity}

Cell proliferation and viability was affected by the substrate (actuator vs. customized cell culture dish). Viability was significantly decreased in the groups grown on the device surface (see Fig. 9).

Although viability seems to be consistently and slightly higher in the group subjected to stimulation, differences were not statistically significant.

\subsubsection{Total protein content}

There were no significant differences in total protein content in control standard dishes, dynamic and static devices groups. Protein values were used to normalize NO values.

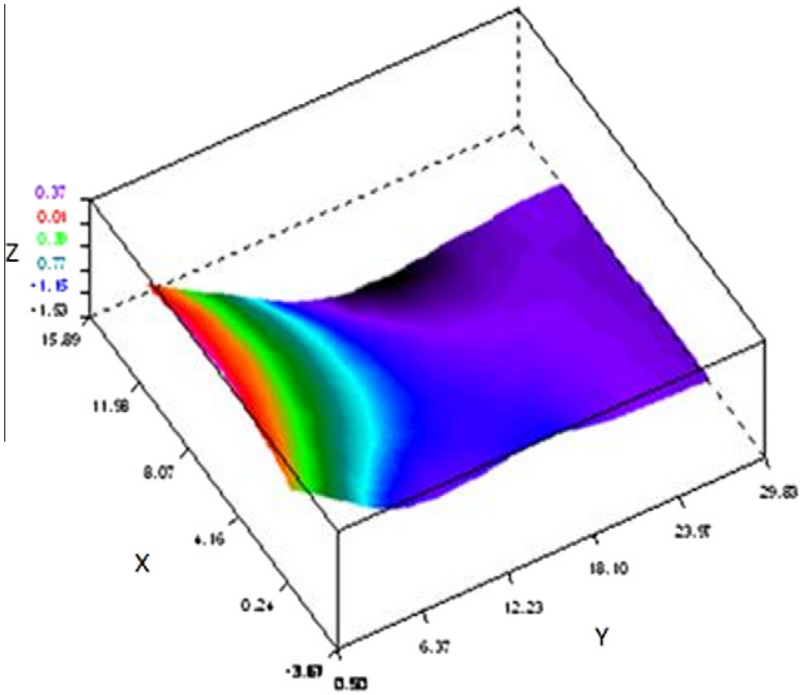

\section{Deformat ion [um] \\ $P V=1898$}

30.03.2002 11:1107

LOME

Fig. 7. Displacement variation tridimensionally along uncoated PVDF actuator surface (axis-zz), using EPSI.

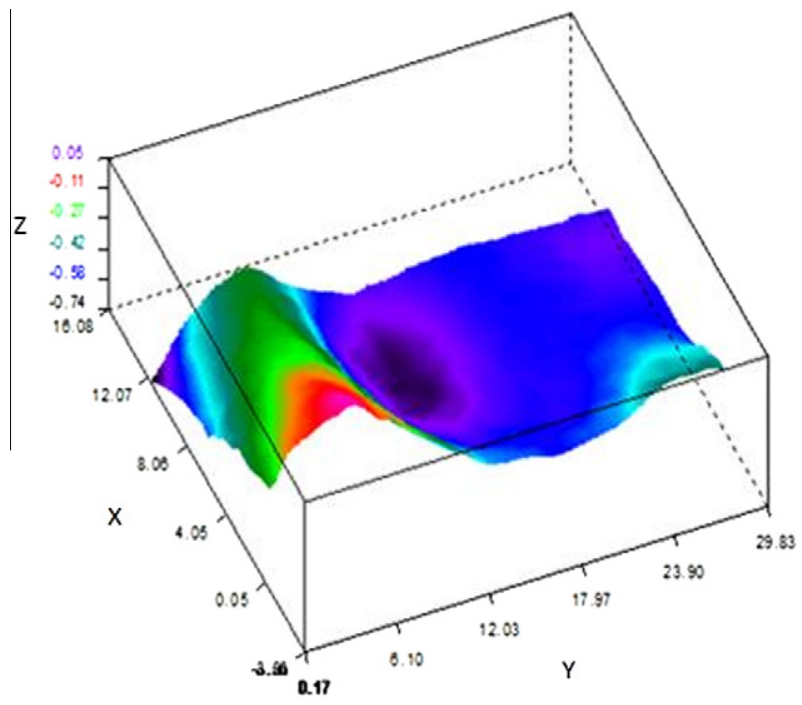

Deformation [um]

$\mathrm{PV}=0.790$

30-03-2009 1127:02

LOME

Fig. 8. Displacement variation tridimensionally along coated PVDF actuator surface (axis-zz), using EPSI.

\subsubsection{Nitric oxide}

Nitric oxide in culture medium after stimulation was significantly higher in dynamic conditions vs. static, $24 \mathrm{~h}$ after seeding (see Fig. 10).

\section{Discussion and conclusions}

In this work the maximum strain was constant, $\varepsilon_{y y}=2211 \mu \varepsilon$ because the applied voltage was constant, although the frequency 


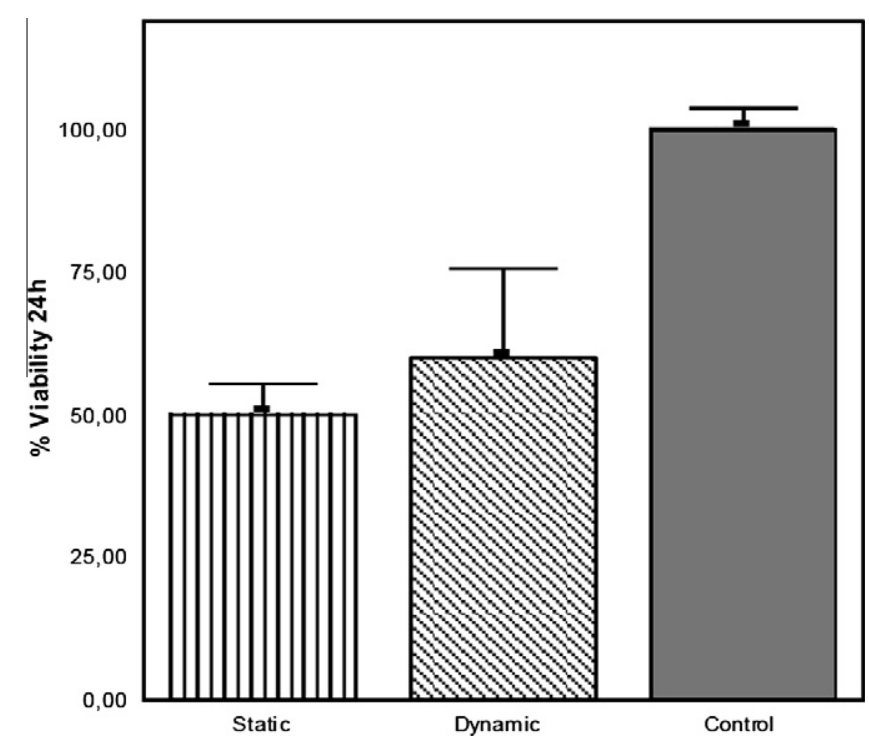

Fig. 9. Cell viability 24 after seeding and daily stimulation of the dynamic group, results are expressed in percent related to controls (standard cell culture dish, TPP). Bars show means and error bars show means \pm standard error of the mean.

varied. The deformation along the piezoelectric material was assumed as acceptable. Often, the in vitro studies published on bone cells mechanical stimulation do not provide information on the displacement and little is known about the minimum strain that is capable of eliciting a response in vivo. Bhatt et al. have shown cultured osteoblasts response to substrate strains in the order of 3-9\% [34]. In vivo the maximum strains in human long bones are in the order of $2000-4000 \mu \varepsilon$ but it is difficult to compare the magnitudes of strains in vitro with the in vivo, because they differ in their characteristics [35]. Based in in vitro studies, we know strain magnitude and frequency influence the gene expression, activating different pathways of cell response; higher strain causes a response that differs from the one present at lower strains $[34,36]$. The present study shows that cells detect and respond to low substrate deformation values in a reproducible manner.

The results suggest that the devices (coated piezoelectric substrate) affected negatively cell viability and proliferation. Although

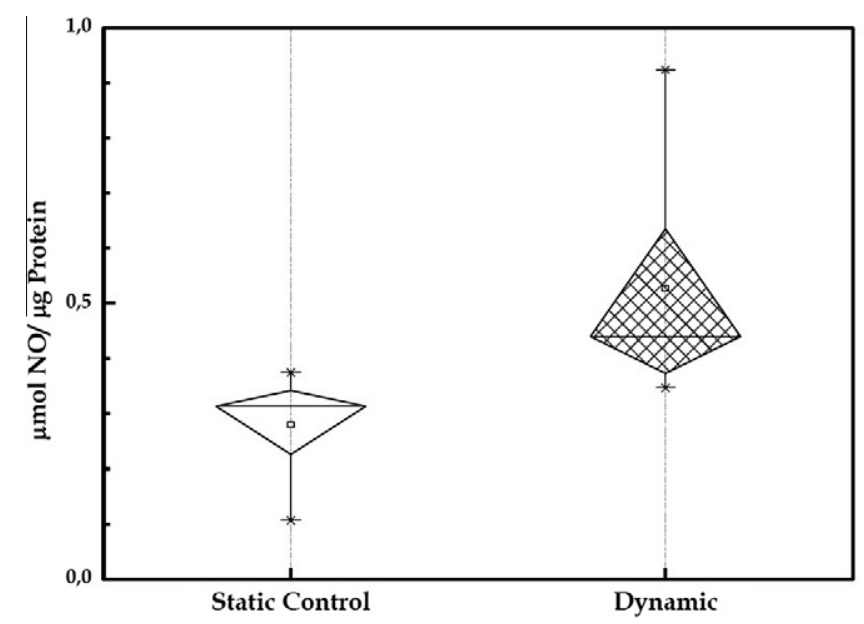

Fig. 10. NO measurement $(\mu \mathrm{mol} / \mathrm{ml})$ in culture medium vs. total protein content $(\mu \mathrm{g} / \mathrm{ml})$ in static vs. dynamic conditions, $24 \mathrm{~h}$ after seeding МC3T3 on the devices, and immediately after stimulation at 1 and $3 \mathrm{~Hz}$. NO values are significantly higher in the dynamic group. The results follow a normal distribution. Mean \pm SEM. Static 24 h $2.0 \pm 0.35$; dynamic 24 h $3.7 \pm 0.65$; static 48 h $1.7 \pm 0.30$; dynamic 48 h $3.2 \pm 0.54$.
Braga et al. did find no evidence of deleterious effects of extracts obtained from PVDF/HA [37], the few studies on PVDF cytocompatibility using adherent cell lines indicate inhibitory effects on proliferation and differentiation [38,39], stronger than the ones reported in this study. The coating procedure and materials used in the present study aimed not only electrical insulation but improvement of cell adhesion.

Apart from the impact of the PVDF itself, the coating might improve or diminish protein adsorption and cell adhesion. For adherent cell lines like MC3T3, this is of extreme importance. Surface properties are also influenced by the sterilization method. In this study, $\gamma$-irradiation was used to sterilize the devices; this method may increase protein adsorption and cause coating oxidation phenomena [40]. In the present study, no in-depth study was conducted on eventual oxidation phenomena on the surface of the devices. It is known that polymers, including PMMA, when subjected to high energy irradiation undergo structural changes, with radical formation and scysson phenomena, leading to change of mechanical properties in a dose-dependent manner [41,42]. PMMA samples subjected to irradiation doses of $20 \mathrm{kGr}$ show oxidation, chain scysson and a lower molecular weight, favoring a more ductile behavior that might be beneficial in the present experimental conditions [43]. Material changes can be seen, also, in other sterilization techniques such as ethylene oxide, ultraviolet radiation and even low temperature plasma sterilization.

The slightly higher values of resorufin in the dynamic group are in harmony with the expected proliferation enhancement related to the mechanical stimulation, in accordance with the literature $[15,20,44]$.

The rise in the NO values in the culture medium under dynamic conditions suggests that piezoelectric materials can be effective mechanical stimuli generators. The protein content and the resarzurin tests show no deleterious effects of the electrical stimulation of the devices, since no significant differences were found between static and dynamic groups. This supports the hypothesis that the inverse piezoelectric effect can be explored as a mean of mechanically stimulate bone and other tissues, allowing the control of mechanical ranges stimulation by the amount of electrical energy applied, ensuring a wide range of frequencies due to swift answer. Another aspect is the possibility by changing the piezoelectric constants of a biocompatible piezoelectric material stimulate bone in different directions apart the one used in this work $\left(d_{y y}\right)$. The potential for development and application of novel piezoelectric composites based upon the lessons drawn from nature is, therefore, remarkable.

\section{Acknowledgements}

The authors would like to thank the Portuguese Foundation for Science and Technology (FCT) for financial support under the Grant PTDC/EMEPME/70155/2006 Grants SFRH/BD/22856/2005 and SFRH/BD/31895/2006, to INEB (OPorto) and ITN (Lisbon), especially to Prof. Doutora Luísa Botelho.

\section{References}

[1] Weiner S, Traub W, Wagner HD. Lamellar bone: structure-function relations. J Struct Biol 1999;126(3):241-55.

[2] Heinonen A, Oja P, Kannus P, Sievanen H, Haapasalo H, Manttari A. Bone mineral density in female athletes representing sports with different loading characteristics of the skeleton. Bone 1995;17(3):197-203.

[3] Carter DR, Beaupré GS. Skeletal tissue histomorphology and mechanics, in skeletal function and form. Cambridge: Cambridge University Press; 2001.

[4] Turner CH, Owan I, Takano Y. Mechanotransduction in bone: role of strain rate. Am J Phys Endocrinol Metab 1995;269(3):E438-42.

[5] Burr DB, Robling AG, Turner $\mathrm{CH}$. Effects of biomechanical stress on bones in animals. Bone 2002;30(5):781-6.

[6] Cullen DM, Smith RT, Akhter MP. Bone-loading response varies with strain magnitude and cycle number. J Appl Phys 2001;91(5):1971-6. 
[7] Hsieh YF, Turner $\mathrm{CH}$. Effects of loading frequency on mechanically induced bone formation. J Bone Miner Res 2001;16(5):918-24.

[8] Robling AG, Burr DB, Turner $\mathrm{CH}$. Recovery periods restore mechanosensitivity to dynamically loaded bone. J Exp Biol 2001;204(19):3389-99.

[9] Tanaka SM, Li J, Duncan RL, Yokota H, Burr DB, Turner CH. Effects of broad frequency vibration on cultured osteoblasts. J Biomech 2003;36(1):73-80.

[10] Turner $\mathrm{CH}$. Three rules for bone adaptation to mechanical stimuli. Bone 1998;23(5):399-407.

[11] Kanamaru Y, Takada T, Saura R, Mizuno K. Effect of nitric oxide on mouse clonal osteogenic cell, MC3T3-E1, proliferation in vitro. Kobe J Med Sci $2001 ; 47(1): 1-11$.

[12] Bakker AD, Soejima K, Klein-Nulend J, Burger EH. The production of nitric oxide and prostaglandin E2 by primary bone cells is shear stress dependent. J Biomech 2001;34(5):671-7.

[13] Smalt R, Mitchell FT, Howard RL, Chambers TJ. Induction of NO and prostaglandin E2 in osteoblasts by wall-shear stress but not mechanical strain. Am J Phys Endocrinol Metab 1997;273(4):E751-8.

[14] Fan X, Rahnert JA, Murphy TC, Nanes MS, Greenfield EM, Rubin J. Response to mechanical strain in an immortalized pre-osteoblast cell is dependent on ERK1/2. J Cell Phys 2006;207(2):454-60.

[15] Kadow-Romacker A, Hoffmann JE, Duda G, Wildemann B, Schmidmaier G. Effect of mechanical stimulation on osteoblast- and osteoclast-like cells in vitro. Cells Tissues Organs 2009;190(2):61-8.

[16] Fukada E, Yasuda I. On the piezoelectric effect of bone. J Phys Soc Jpn 1957;12(10):1158-62.

[17] Wang T, Feng Z, Song Y, Chen X. Piezoelectric properties of human dentin and some influencing factors. Dent Mater 2007;23(4):450-3.

[18] Fukada E. History and recent progress in piezoelectric polymers. IEEE T Ultrason Ferr 2000;47(6):1277-90.

[19] Halperin C, Mutchnik S, Agronin A, Molotskii M, Urenski P, Salai M, et al. Piezoelectric effect in human bones studied in nanometer scale. Nano Lett 2004;4(7):1253-6.

[20] Lewandowska-Szumiel M, Sikorski K, Szummer A, Lewandowski Z, Marczynski W. Osteoblast response to the elastic strain of metallic support. J Biomech 2007;40(3):554-60

[21] Brown TD. Techniques for mechanical stimulation of cells in vitro: a review. Biomech 2000;33(1):3-14.

[22] McGarry JG, Maguire P, Campbell VA, O'Connell BC, Prendergast PJ, Jarvis SP. Stimulation of nitric oxide mechanotransduction in single osteoblasts using atomic force microscopy. J Orthop Res 2008;26(4):513-21.

[23] Appleford MR, Oh S, Cole JA, Protivínský J, Ong JL. Ultrasound effect on osteoblast precursor cells in trabecular calcium phosphate scaffolds. Biomaterials 2007;28(32):4788-94.

[24] Tanaka SM. A new mechanical stimulator for cultured bone cells using piezoelectric actuator. J Biomech 1999;32(4):427-30.

[25] Rodrigues MT, Gomes ME, Mano JF, Reis RL. B-PVDF membranes induce cellular proliferation and differentiation in static and dynamic conditions. Mater Sci Forum 2008;587-588:72-6.

[26] Sudo H, Kodama HA, Amagai Y, Yamamoto S, Kasai S. In vitro differentiation and calcification in a new clonal osteogenic cell line derived from newborn mouse calvaria. J Cell Biol 1983;96(1):191-8.
[27] Saunders MM, You J, Trosko JE, Yamasaki H, Li Z, Donahue HJ, et al. Gap junctions and fluid flow response in MC3T3-E1 cells. Am J Phys Cell Phys 2001;281(6):C1917-25

[28] Liu D, Genetos DC, Shao Y, Geist DJ, Li J, Ke HZ, et al. Activation of extracellularsignal regulated kinase (ERK1/2) by fluid shear is $\mathrm{Ca}^{2+}$ - and ATP-dependent in MC3T3-E1 osteoblasts. Bone 2008;42(4):644-52.

[29] Jaasma MJ, O'Brien FJ. Mechanical stimulation of osteoblasts using steady and dynamic fluid flow. Tissue Eng Part A 2008;14(7):1213-23.

[30] Ansar Ahmed S, Gogal Jr RM, Walsh JE. A new rapid and simple non-radioactive assay to monitor and determine the proliferation of lymphocytes: an alternative to $[3 \mathrm{H}]$ thymidine incorporation assay. J Immunol Methods 1994;170(2):211-24.

[31] Zhi-Jun Y, Sriranganathan N, Vaught T, Arastu SK, Ansar Ahmed S. A dye-based lymphocyte proliferation assay that permits multiple immunological analyses: mRNA, cytogenetic, apoptosis, and immunophenotyping studies. J Immunol Methods 1997;210(1):25-39.

[32] Slaughter MR, Bugelski PJ, O'Brien PJ. Evaluation of alamar blue reduction for the in vitro assay of hepatocyte toxicity. Toxicol in Vitro 1999;13(4-5): 567-9.

[33] Rob J, Hof SHR van'T. Nitric oxide and bone. Immunology 2001;103(3):255-61.

[34] Bhatt KA, Chang EI, Warren SM, et al. Uniaxial mechanical strain: an in vitro correlate to distraction osteogenesis. J Surg Res 2007;143(2):329-36.

[35] Burr DB, Milgrom C, Fyhrie D, et al. In vivo measurement of human tibial strains during vigorous activity. Bone 1996;18(5):405-10.

[36] Tang L, Lin Z, Li Y-M. Effects of different magnitudes of mechanical strain on osteoblasts in vitro. Biochem Biophys Res Commun 2006;344(1):122-8.

[37] Braga FJC, Rogero SO, Couto AA, Marques RFC, Ribeiro AA, Campos JSDC. Characterization of PVDF/HAP composites for medical applications. Mater Res 2007; 10:247-51.

[38] Tabary N, Lepretre S, Boschin F, Blanchemain N, Neut C, Delcourt-Debruyne E, et al. Functionalization of PVDF membranes with carbohydrate derivates for the controlled delivery of chlorhexidin. Biomol Eng 2007;24(5): $472-6$

[39] Hung C-H, Lin Y-L, Young T-H. The effect of chitosan and PVDF substrates on the behavior of embryonic rat cerebral cortical stem cells. Biomaterials 2006;27(25):4461-9.

[40] Lleixà Calvet J, Grafahrend D, Klee D, Möller M. Sterilization effects on starPEG coated polymer surfaces: characterization and cell viability. J Mater Sci: Mater M 2008;19(4):1631-6.

[41] Güven O, Uzun C. A comparative study of thermal and mechanical stabilities of gamma irradiated PMMA, PP and PVC. Radiat Phys Chem 1993;42(46):1047-50.

[42] Croonenborghs B, Smith MA, Strain P. X-ray versus gamma irradiation effects on polymers. Radiat Phys Chem 2007;76(11-12):1676-8.

[43] Suarez JCM, Mano EB, Monteiro EEDC, Tavares MIB. Influence of gammairradiation on poly(methyl methacrylate). J Appl Polym Sci 2002;85(4):886-95.

[44] Fermor B, Gundle R, Evans M, Emerton M, Pocock A. Primary human osteoblast proliferation and prostaglandin E2 release in response to mechanical strain in vitro. Bone 1998;22(6):637-43. 